
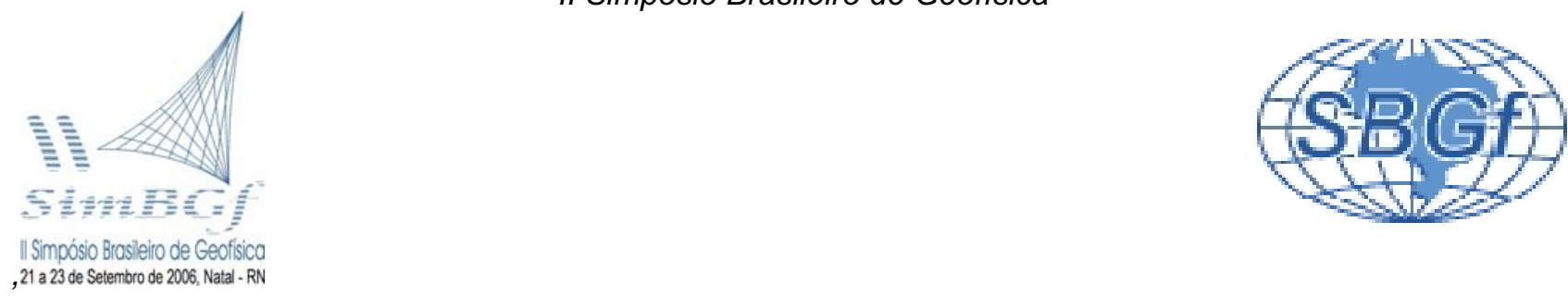

\title{
Direct detection of ctrmination using GPR
}

L. A. Peche, J. M. Travassos, Observatório Nacional, Rio de Janeiro, RJ, Brazil

Email: peche@on.br, jandyr@on.br

Copyright 2006, SBGf-Sociedade Brasileira de Geofísica

Este texto foi preparado para a apresentação no II Simpósio de Geofísica da Sociedade Brasileira de Geofísica, Natal, 21-23 de setembro de 2006. Seu conteúdo foi revisado pela Comissão Tecno-científica do II SR-SBGf mas não necessariamente representa a opinião da SBGf ou de seus associados. E proibida a reprodução total ou parcial deste material para propósitos comerciais sem prévia autorização da SBGf.

In this work we performed a multi-resolution spectral analysis of a GPR profile using the continuous wavelet transform (CWT). The mother wavelet was an orthogonal Daubechies wavelet of fifth order. The spectral contents of the GPR signal is analyzed and eventually transformed back to the time domain using wavelet packets. We show here that the presence of the gasoline is reflected in the spectral contents of the GPR trace.

Keywords - GPR imaging; spectral decomposition; wavelet package; hydrocarbon contamination.

\section{Introduction}

The uncontrolled disposal of Non-Aqueous Phase Liquids (NAPLs) such as petroleum fuels, chlorinated solvents, coal-tars and other mobile hydrocarbons poses serious groundwater, land and public health problems throughout the world. The assessment of time-varying concentrations and sub-surface distribution of NAPLs can be extremely difficult, requiring expensive programs of site investigation, distribution modeling, excavation, drilling and sampling. This is why non-invasive geophysical investigation techniques have become increasingly prevalent with GPR being one of the most popular. Unfortunately a high percentage of GPR investigations focus on event location and mapping only disregarding the need to extract material property information from the data. That information may be obtained directly from the GPR data through the use of attribute analysis methods, e.g. spatial variation in signal attenuation, wave velocity, spectral decomposition, etc. The objective is the knowledge of a direct relation of those geophysical properties to the macroscopic dielectric parameters, i.e., the permittivity and conductivity, of the contaminating fluids.

On the same token that may be difficult to directly detect LNAPLs in the data by visual inspection the analysis of wave velocity from the GPR data may be tricky as CMP gathers are prone to suffer from degradation of coherence peaks with depth due to their limited short spread imposed by the high signal absorption and the short distances needed to reach the far-field (Yilmaz, 2001). We expect that lack of resolution in the velocity spectrum may give rise to errors in the estimates of velocity that are comparable, or even greater than the expected difference in velocity caused by the presence of the contaminant (Carcione et al., 2000; Cassidy, 2004).

Spectral decomposition aims to characterize a timedependent frequency response of the subsurface as seen in seismic data over reservoir rocks. In principle there is no reason that analysis should not be used for GPR data as well. For instance frequency spectral analysis was applied to analyze spectral attributes of the frequency spectra as they change laterally and in time over a crude oil spill (Burton et al., 2004).

Spectral decomposition methods such as short-window discrete Fourier transform (SWDFT), wavelet transform (WT) ( Sadowsky, 1996; Torrence et al, 1998) and Matching Pursuit Decomposition (Mallat et al, 1993) have been extensively used for spectral decomposition of seismic data. This attribute have been used in estimating tuning thickness, mapping stratigraphic variability and for analyzing direct hydrocarbon indicators (Chakraborty \& Okaya, 1995; Partyka et al., 1999; Castagna et al., 2003 ; Sinha et al., 2005).

The analysis window length of SWDFT and WT differ as the former uses fixed-length whereas the former uses a variable length, which is inversely proportional to the frequency being analyzed. WT thus provide the maximum temporal resolution of focused regions. This characteristic of the WT makes it our choice for analyzing an eventual direct hydrocarbon indicator.

\section{The Experiment}

The experiment was carried out in a University farmland in Santa Catarina Island, southeastern Brazil. The local geology is characterized by unconsolidated deposits of eolian, alluvial, lacustrine and marine sands. The soil is a gray-brown loamy sand on the top of fine grained sand with less than $5 \%$ of silt and clay. Depth to the seasonal water table was $2 \mathrm{~m}$. The horizontal gradient at the site is $1.8 \%$, with a hydraulic conductivity of $10-4 \mathrm{~cm} / \mathrm{s}$ and effective porosity of 0.20 , giving a groundwater flow of 2.8 $\mathrm{m} / \mathrm{yr}$ (Corseuil et al, 2000). The area has been used for geochemical data collection on monitoring natural attenuation of controlled spills of LNAPLs since 1998 (Corseuil et al, 2000).

A controlled spill was carried out on December 22, 2004, as part of a geochemistry experiment, where 13 I of an aqueous solution of $500 \mathrm{~g}$ of $\mathrm{KBr}$, added to $100 \mathrm{I}$ of Brazilian gasoline containing $24 \%$ ethanol, were poured on a $1 \mathrm{~m} \times 1 \mathrm{~m} \times 1 \mathrm{~m}$ hole. The hole is at the NNW end of 
the area of the experiment, a rectangular area covered with monitoring wells, its largest dimension coinciding with the groundwater flow. Figure 1 shows the location of the first $7 \mathrm{SW}$-NE rows of monitoring wells, closer to the hole. Each well is a multi-level sampling well that allow the collection of water samples at 5 depths ranging from 1 to $4 \mathrm{~m}$. The materials employed in the wells are PVC and polyethylene (Figure 1). $\mathrm{KBr}$ was used as a tracer as it is not present in any significant amount in groundwater (Corseuil et al, 2000). After the spill the hole was filled up with soil and the whole area covered with a black plastic tarp.

Eight fixed offset and thirteen CMP profiles were collected with a Pulse Ekko 100 in January, just after the first geochemical campaign. That was followed by a second geophysical campaign in February comprising of more CMP profiles and a 3-D VES in the area. All the GPR data were collected with $200 \mathrm{MHz}$ antennae, 400 ps sampling rate, 32 stack, and $0.1 \mathrm{~m}$ spatial sampling with stop-andgo firing. All GPR profiles are $9 \mathrm{~m}$ in length and run along NW to SE and SW to NE directions, close to the wells seen in Figure 1.

The CMP profiles in the study area show essentially a two-velocity model with $0.09-0.12 \mathrm{~m} / \mathrm{ns}$ down to $1 \mathrm{~m}$ and then a lower velocity $0.04-0.07 \mathrm{~m} / \mathrm{ns}$. A level-run (RAMAC $100 \mathrm{MHz}$ borehole antennae, $0.2 \mathrm{~m}$ step size) done using two wells $20 \mathrm{~m}$ apart, $30 \mathrm{~m}$ to the west from the center of the hole, estimated the velocity from 1 to 4 $\mathrm{m}$ depth as $0.072-0.074 \mathrm{~m} / \mathrm{ns}$. We rather accept the borehole estimate and adopt the following velocity model: $0.1 \mathrm{~m} / \mathrm{ns}(0-1 \mathrm{~m}), 0.07 \mathrm{~m} / \mathrm{ns}(1-4 \mathrm{~m}$ ].

In this work we are going to concentrate on a single EW fixed offset profile shown in Figure 1.

The first geochemical campaign in January 2005 detected ethanol and BTEX compounds only in well $(3,3)$, right at the center of the hole. In February a second campaign detected ethanol and BTEX in wells $(3,3)$ and $(4,3)$ only (Corseuil, 2005). Please refer to Figure 1 for the adopted reference frame all elements are referenced to. During the first geophysical campaign in January we were able to smell gasoline vapors in nine of the monitoring wells: $(1,3),(2,3),(3,2),(3,3),(3,4),(4,2),(4,3),(5,2),(5,4)$. This indicates that although a dissolved phase may have migrated some more than $1 \mathrm{~m}$ to the SE, a sizable vapor phase of more than $3 \mathrm{~m}$ in diameter developed with well $(3,3)$ at its center.

\section{Metodology}

We perform the spectral decomposition using the WT in order to assure maximum temporal resolution of the study area. The limitation in this approach is that it has good time resolution at higher frequencies and good frequency resolution at lower frequencies. Techniques as wavelet packet decomposition (WPD) (Coifman et al., 1992) e matching pursuit decomposition (MPD) (Mallat et al., 1993). Those have been used in seismics (Chakraborty et al., 1995; Sinha et al, 2005). We use the WPD in this work as a multi-resolution tool to analyze the spectral contents of our data.
The continuous WT (CWT) describes the signal S(t) with an orthogonal basis $\psi_{b, a}$, which is generated with dilations ( $a$ ) and translations ( $b$ ) of a mother wavelet

$$
\psi_{b, a}=\psi\left(\frac{t-b}{a}\right)
$$

compact and localized in time. We then can map the transformed signal in a scalogram, i.e., a scale-time section, in which large scales correspond to lower frequency components and vice-versa.

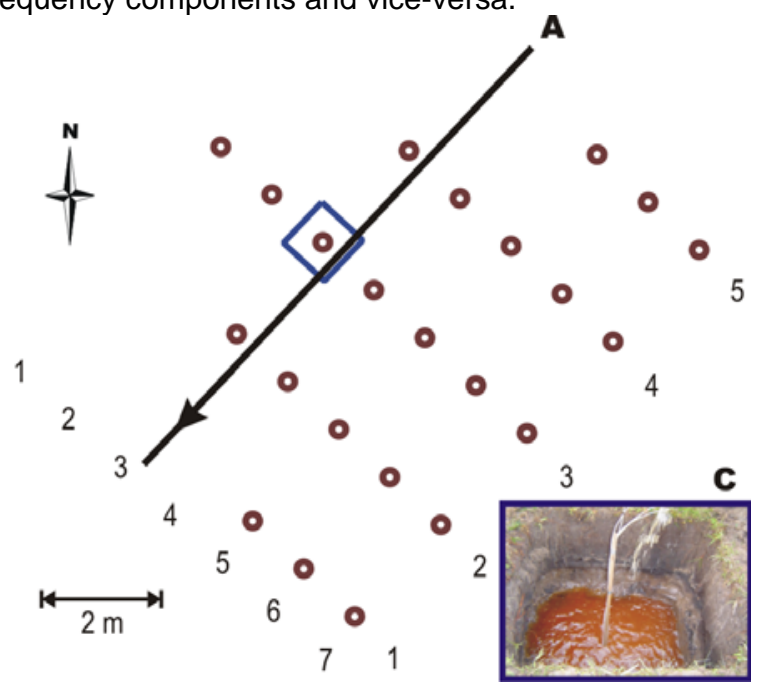

Figure 1: Map of the study area containing the elements referred to in the text, referenced to an arbitrary reference frame with axis running NW to SE and SW to NE. In this manner, a particular element is referenced to by a pair of integers $(n, m)$, running $N W$ to SE and SW to NE respectively. The blue square centered at $(3,3)$ indicates the hole where the gasoline was poured in. The inset $C$ shows a picture of the hole filled with gasoline, having a monitoring well at its center. The monitoring wells are shown as open magenta circles; the northwesternmost well is at position $(1,3)$. A is the GPR profile referred to in the text, arrowed to indicate the direction of measurement.

We can transform the scalogram into a time-frequency section if we approximate any given frequency by the central frequency of the wavelet. The latter being inversely proportional to the scale (Abry et al., 1993; Hlawatsch et al., 1992).

$$
f=\frac{K_{\psi}}{a}
$$

where $K_{\psi}$ is a constant that depends on the choice of the wavelet.

We can transform the WT back to the signal $\mathrm{S}(\mathrm{t})$ via the continuous inverse wavelet transform (CIWT). This exists as long as it meets than admissibility condition. In practice there is a factor that hinder the use of the CIWT. First the CIWT is redundant. To deal with this limitation we use the discrete wavelet transform (DWT). Here we use a generalization of the DWT known as Wavelet 
Packet Decomposition (WPD). The advantage here is we can achieve better resolution for the higher frequencies. The WPD is based on a dictionary of basis called wavelets packets.

With the WPD we can reconstruct $S(t)$ with a selected range of frequencies. Those frequencies can in turn be chosen by their importance in describing a given response. Here we concentrate on the spectral characteristics that may have appeared in $\mathrm{S}(\mathrm{t})$ as a result of the presence of the gasoline.

\section{Results}

The processing of the GPR data comprised of a 4 step procedure: data editing, pre-processing, trace equalization and spectral decomposition. The preprocessing stage consisted of dewow, and a judicious AGC gaining stage, mild enough not to saturate any trace. We did not filter our GPR data so as not to interfere later with the process of spectral decomposition. The traces were equalized in amplitude gaining the traces with the inverse of the envelope, obtained with the Hilbert transform of the trace. The resulting GPR section is in Figure 2.

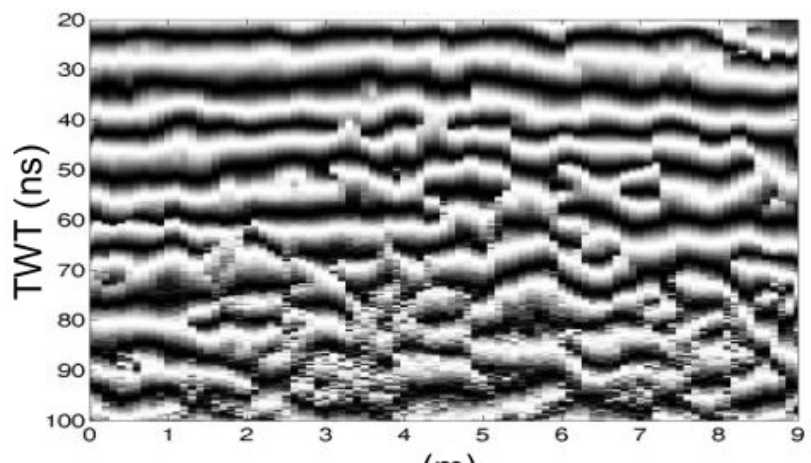

(m)

Figure 2: GPR section of the fixed-offset profile A shown in Figure 1.

We begin our analysis choosing three traces, one right at the center of the hole at $(3,3)$, or $4.5 \mathrm{~m}$, and two at the ends of the profile $A$ at $(3,5)$, or $0 \mathrm{~m}$, and at $(3.1)$, or $8 \mathrm{~m}$. We estimate the CWT using an orthogonal Daubechies wavelet of $5^{\text {th }}$ order. The time-frequency sections and the FFT spectrum of these traces is shown in Figure 3 . The CWT shows an energy loss in the range $[50,80]$ ns. Note that the FFT spectrum of trace $(3,3)$ is conspicuously less energetic than the other traces'.

Figure 3 suggests that the presence of the gasoline is seen in the spectral components obtained with the CWT. We then proceed to decompose the entire section shown in Figure 2 with WPD. We use the same mother wavelet and perform the WPD down to level 6 to produce 63 spectral components. Each of those representing a given frequency range. Figure 4 shows the WPD component $W_{6,6}$ of trace $(3,3)$ at $4.5 \mathrm{~m}$ as well as its time-frequency section and its Fourier spectrum. Assuming that the hydrocarbon influence is stronger in that component then its spectral influence falls around $80 \mathrm{Mhz}$ with a dispersion of $20 \mathrm{Mhz}$. It is important to stress here that there is no reason to generalize this to other GPR frequencies.
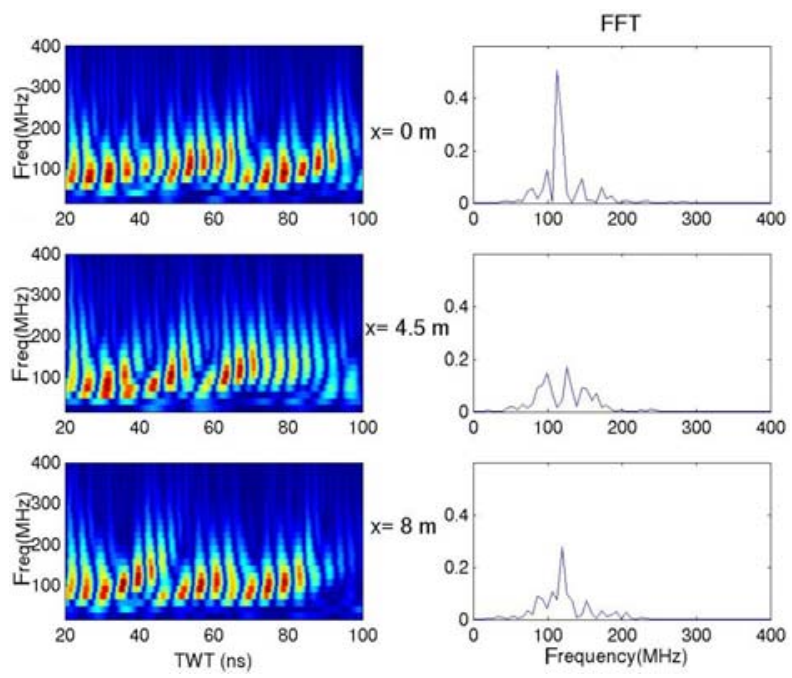

Figure 3: Time-frequency sections and the FFT spectrum of three traces at: $0,4.5$, and $8 \mathrm{~m}$.
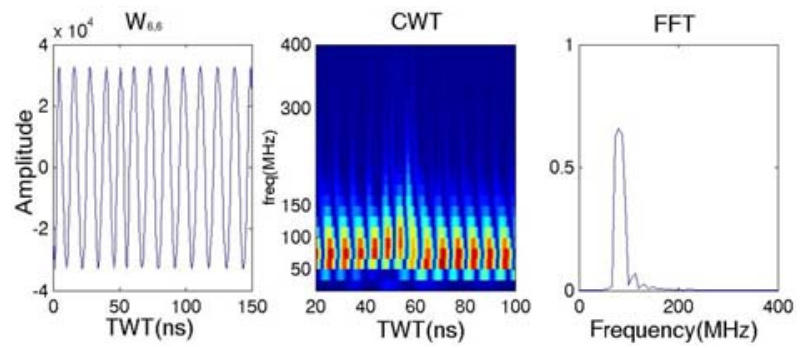

Figure 4: Left panel show the WPD component $W_{6,6}$ of trace $(3,3)$ at $4.5 \mathrm{~m}$. Middle panel gives its timefrequency section. The FFT of the $W_{6,6}$ component is in the right panel.

Once recognized the WPD component that is more affected by the presence of the gasoline, i.e., $W_{6,6}$, we proceed transforming the whole section of Figure 2 . We then transform back to the $x$-t domain via the IWT. The result is in Figure 5. Not surprising all the geometric information in Figure 2 is lost, but the area around the hole $(3,3)$ is retained in the section. That may be delineating the influence of one or two of the phases of the hydrocarbon in the subsurface: the free-phase or the vapor-phase. 


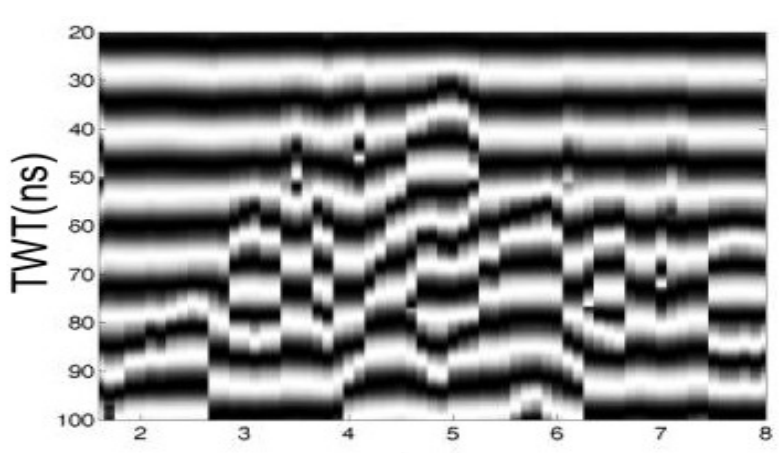

$(\mathrm{m})$

Figure 2: Inverse of the component $W_{6,6}$, in the $x-t$ domain.

\section{Conclusions}

A multi-resolution spectral analysis of a GPR profile done in this work successfully revealed the spectral contents of the GPR signal over a controlled LNAPL spill. Using the continuous wavelet transform we show here that the presence of the gasoline is reflected in the spectral contents of the GPR trace.

The spectral contents of the GPR signal is analyzed and eventually transformed back to the time domain using wavelet packets. We show here that the presence of the gasoline is reflected in the spectral contents of the GPR trace. With this is possible to transform back to the $x-t$ domain a single component of the WPD to produce a GPR section delineating the influence of one or two of the phases of the hydrocarbon in the subsurface: the freephase or the vapor-phase. Of course by the volume of the anomalous part in the resulting section the main contribution probably comes from the vapor phase. It remains the need of a modeling exercise in order to corroborate this assumption.

\section{Acknowledgement}

This work was funded by Petrobras. JT is a recipient of a research scholarship from CNPq.

\section{References}

Abry, P., P. Goncalves, and P. Flandrin, 1993, Waveletbased spectral analysis of 1/f processes: International Conference on Acustic, Speech and Signal Processing, IEEE, Proceedings, 3, 237-240.

Burton, B.L., Olhoeft, G. R., Powers, M. H., 2004, Frequency spectral analysis of GPR data over a crude oil spill, Tenth International Conference on Ground Penetrating Radar, 21-24 June, 2004, Delft, The Netherlands: $4 \mathrm{p}$.

Cassidy, N. J., 2004, Dielectric and GPR behavior of freephase NAPL mixtures: implications for the practical assessment of hydrocarbon contamination, Tenth International Conference on Ground Penetrating Radar, 21-24 June, 2004, Delft, The Netherlands: 4p.

Carcione, J.M., Marcak, H., Seriani, G, Padoan, G., 2000, GPR modeling study in a contaminated area of Kryzywa Air Base (Poland), Gophys., 65: 521-525.
Castagna, J.P., Sun, S., Siegfried, R.W., 2003, Instantaneous spectral analysis: Detection of lowfrequency shadows associated with hydrocarbons, The Leading Edge, February 2003: 120-127.

Chakraborty, A., Okaya, D., 1995, Frequency-time decomposition of seismic data using wavelet-based methods, Geophys., 60: 1906-1916.

Coifman , R.R., and Wickerhauser, M. V., 1992, Entropybased algorithms for best basis selection, IEEE Trans. Inform. Th., 38, 713-719.

Corseuil, H.X., Fernandes, M., Rosário, M., Seabra, P.N., 2000, Results of a Natural Attenuation Field Experiment for an Ethanol-Blended Gasoline Spill, In: Proceedings of the 2000 Petroleum Hydrocarbons and Organic Chemicals in Ground Water: Prevention, Detection, and Remediation, Anaheim, California, 24-31.

Corseuil, 2005, personal communication

Hlawatsch, F., and G. F. Boudreaux-Bartels, 1992, Linear and quadratic time-frequency signal representations: IEEE Signal Processing, 9, 21-67

Mallat, S., and Zhang, Z., 1993, Matching pursuit with time frequency dictionaries, IEEE Trans. Signal prec., 41, 3397-3415.

Partyka, G., Gridley, J., Lopez, J., 1999, Interpretational applications decomposition in reservoir characterization,The Leading Edge, March 1999: 353360.

Sadowsky, J., 1996, Investigation of signal characteristics using the continues wavelet transform, Jonhs Hopkins Apl Technical Digest, vol. 17 pag.258-269

Sinha, S., Routh, P.S., Anno, P.D., Castagna, J.P., 2005, Spectral decomposition of seismic data with continuouswavelet transform, Geophys., 70: 19-25.

Torrence, C. and Gilbert P. Compo, 1998, A Practical Guige to Wavelet Analysis, Bulletin of the American Meteorological Society, 9 ,61-78

Yilmaz, O., 2001, Seismic Data Analysis, Vol. 1, SEG, Tulsa, 1000p. 